\title{
The Influence of Process Parameters toward Collar Height on Incremental Backward Hole-Flanging Process
}

\author{
M. Fakhruddin a, b, Moch. Agus Choiron ${ }^{\mathrm{b}}$, Anindito P. ${ }^{\mathrm{b}}$ \\ a Politeknik Negeri Malang \\ Jl. Soekarno Hatta No.09, Malang, Indonesia \\ Telephone: (0341) 404424, Fax: (0341) 551708 \\ e-mail: ruudean@gmail.com \\ b Universitas Brawijaya \\ JI. MT. Haryono no. 167, Malang, Indonesia \\ Telephone: (0341) 554291, 587711, Fax: (0341) 554291
}

\begin{abstract}
The experimental study of the influence of process parameters towards collar height on incremental backward hole-flanging (IBHF) process with aluminum plate workpiece was presented in this paper. The effect of process parameters toward collar height which produced by IBHF process was investigated. Experiments were performed with a CNC machine, a $30^{\circ}$ conical forming tool, and aluminum plates. The process parameters are feed speed with two levels, radial forming step size with three, and axial forming step size with three levels. Some parameters were kept constant, i.e., spindle speed, initial hole diameter, final hole diameter, and conical forming tool diameter. Digital Vernier caliper was used to measure the height of the collar. Experimental results of IBHF process have shown that the feed speed (vf) parameter has no effect toward collar height. Increased radial forming step size $(\Delta x / y)$, increased the collar height also. Increased the axial forming step size $(\Delta z)$ reduced the collar height.
\end{abstract}

Keywords: hole-flanging, incremental sheet metal forming, incremental backward.

\section{INTRODUCTION}

The hole-flanging process in the manufacturing industry is one of the processes used in metal forming. The hole flanging process with a collar had been used in general sheet metal forming especially for pipe interconnection. Geometry product on hole-flange commonly connected with certain diameter and high collar. The higher the collar, the larger area was provided to the pipe connection and the stronger the connection.

There are few disadvantages when using conventional hole flanging process. The conventional hole-flanging process provide high cost to produce collars on a complex hole profile with a small batch of production. The high cost in conventional hole-flanging process is required due to complex punch and die designs. One of the solution for sheet metal forming with complex hole and collar profiles with minimal production costs at small production volumes is Incremental Sheet Forming (ISF). In this method, a simple die was used. Conical punch or forming tool and path designed by CNC machine was used to produce hole-flange. A hole with a collar that leads out and on a product with almost all of its work surface was closed, unable to work with the ISF process. The development of the ISF is performed by the form a hole with a collar towards the outward (backward holeflange) as shown in Figure 1.1. The method was developed to form a hole with an outward collar was called incremental backward hole-flanging (IBHF). 


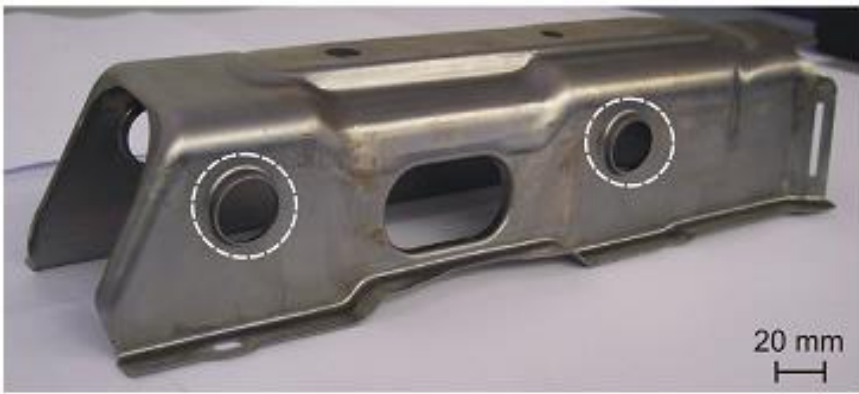

Figure 1.1 hole with outward collar in almost closed surface. Source: Petek and Kuzman [1]

Study on incremental backward hole-flanging process (IBHF) with collar height and thickness as parameter responses was conducted. The material of the plate used in this research is the DC steel 05 . The results of this study indicate that the parameters that have the most significant effect on the height and the thickness of the collar are the diameter of the tool, the magnitude of the radial forming step, and the magnitude of the axial forming step [1]. Incremental forming process for producing prototype parts with round hole-flanges was studied [2]. Forming strategy that increased the part diameter in small steps until it reaches the final optimum part geometry were used. This method can produce a relatively higher collar height, uniform collar thickness and maximum limiting forming ratio (LFR) which is defined as $D / D_{0}$, where $D$ is the finished part diameter, $D_{0}$ denotes the pre-cut hole diameter of plates. The fabrication of conical and cylindrical hole-flanges by ISF was conducted by other researchers [3]. Reducing limitation in process time and geometric accuracy was the objective. Single point incremental forming (SPIF) strategies and process modelling was proposed [4]. New process design to perform ISF was proposed [5]. Investigation on ISF method through a featured tool was conducted [6]. The single point incremental forming (SPIF) also studied with different forming strategy and analysis [7][8]. Thus, more complete forming chain based on ISF can be established [9].

From the literature review that has been mentioned, the effect of process parameters to the height of the collar from the IBHF process will be conducted. Varied parameters include feed speed $\left(V_{t}\right)$ with 2 levels, radial forming step size $(\Delta x / y)$, and axial forming step size $(\Delta z)$ with 3 levels. The material used in this research was Al 1050A and $2 \times 3 \times 3$ full factorial experimental design was used. The experimental and statistical analysis methods to be used to determine the effect of process parameters on the height of the collar produced by incremental backward hole-flanging process.

\section{Methodology}

\subsection{Material and Tools}

The experiment was conducted using MCV 1020 BA CNC milling machine. The conical forming tool was used as punch which was made with High Speed Steel (HSS) using CNC turning machine as shown in Figure 2.1.
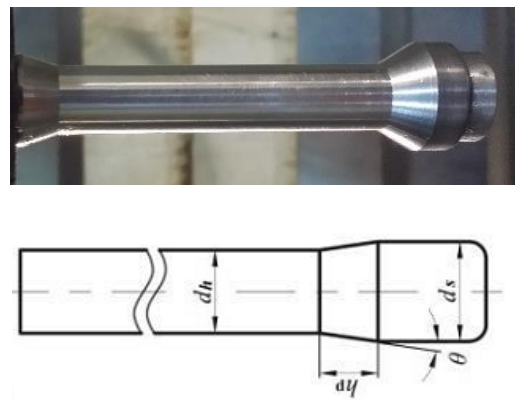

Figure 2.1 Conical tool used on IBHF process. 


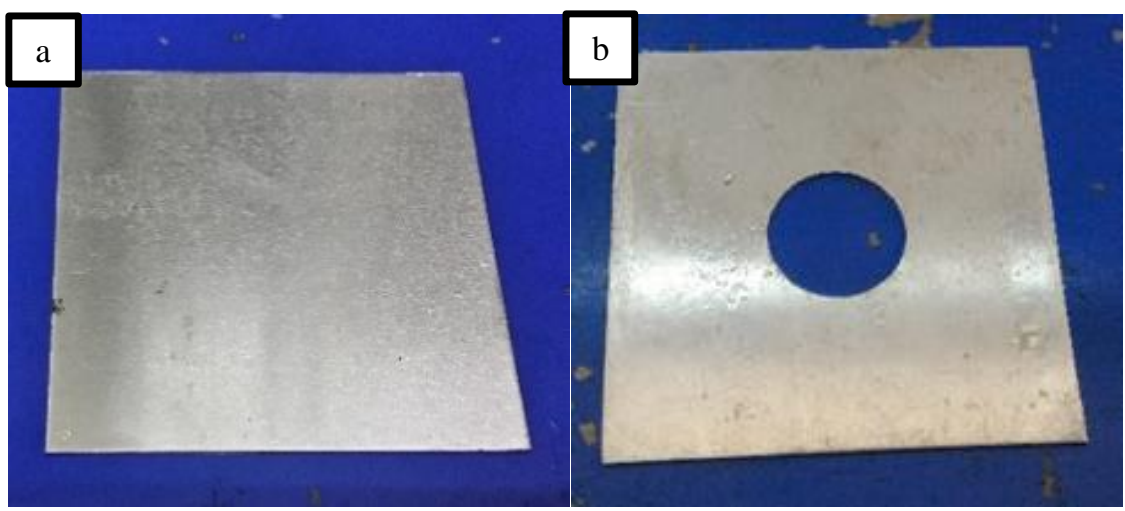

Figure 2.2. Aluminium alloy 1050 A, (a) before (b) after pre-cut.
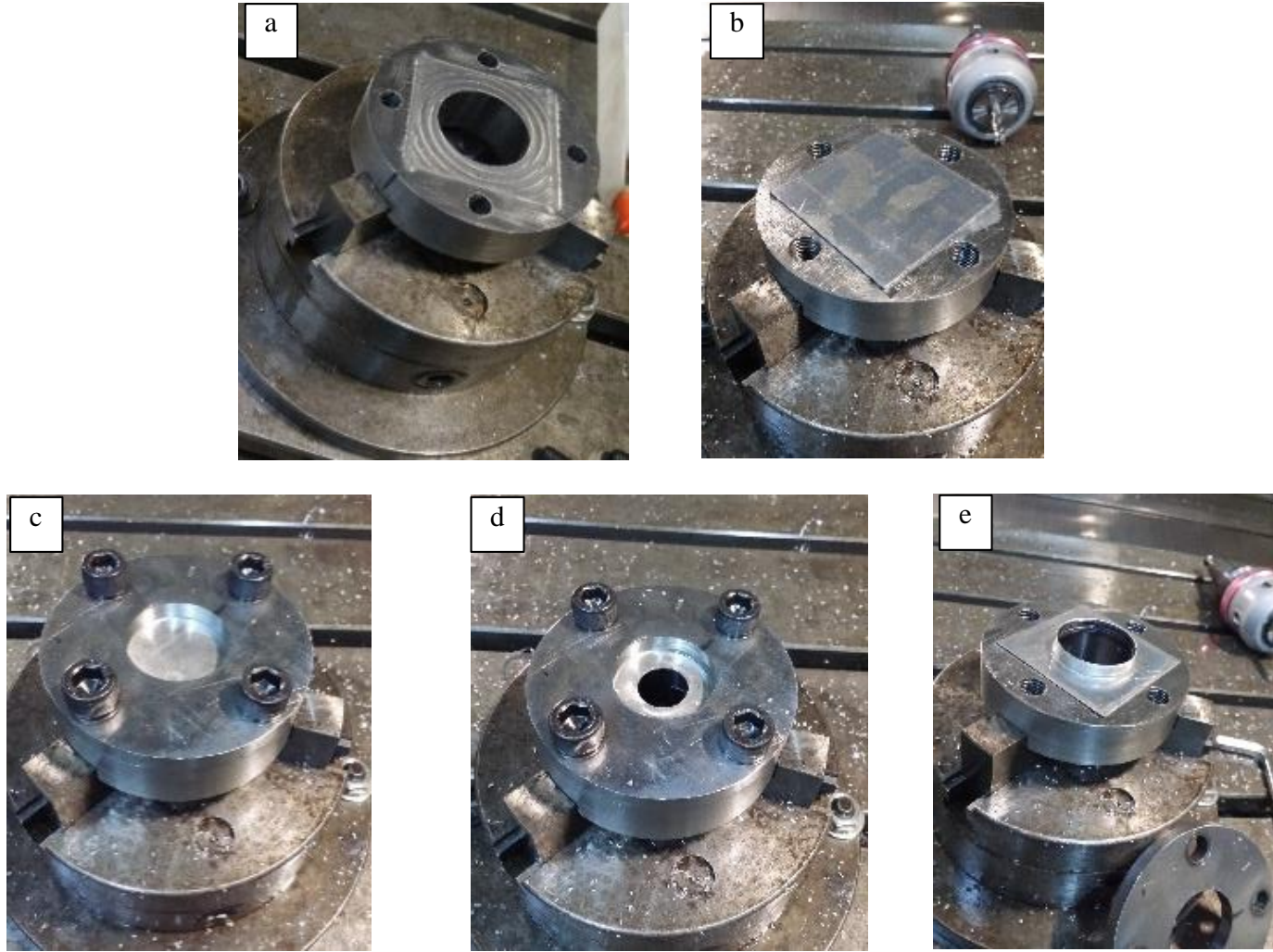

Figure 2.3 Process of alumunium plate held by using jig (a) without plate (b) with plate (c) with plate and upper jig attached (d) after plate was drilled (e) after backward hole-flange was formed.

Al 1050A aluminum alloy plates with a thickness of $1 \mathrm{~mm}$ was used in this IBHF process. The plate was drilled by using milling machine, until diameter $20 \mathrm{~mm}$ of pre-cut hole is achieved, as shown in figure 2.2. The main material mechanical properties, dimension of forming tool and dimension of aluminum plates are presented in Tables 2.1, 2.2 and 2.3. The digital vernier caliper with resolution of $0.01 \mathrm{~mm}$ was used to measure the height of the collar. Jig was used to hold aluminum plate on CNC table. It was specially designed to hold a single $70 \mathrm{~mm} \times 70 \mathrm{~mm} \times 1 \mathrm{~mm}$ aluminum plate, as shown in Figure 2.3. 
Table 2.1 Mechanical properties of Al 1050A

\begin{tabular}{lccc}
\multicolumn{1}{c}{ Element } & Symbol & Unit & Dimension \\
\hline Density & $\rho$ & $\mathrm{Kg} / \mathrm{m}^{3}$ & 2700 \\
Young's Modulus & $\mathrm{E}$ & $\mathrm{GPa}$ & 68 \\
Poisson's ratio & $\mathrm{v}$ & - & 0.33 \\
Yield stress & $\sigma_{\mathrm{s}}$ & $\mathrm{MPa}$ & 90 \\
\hline
\end{tabular}

Table 2.2 Forming tool dimension

\begin{tabular}{lccc}
\hline \multicolumn{1}{c}{ Element } & Symbol & Unit & Dimension \\
\hline Forming Zone & $\mathrm{d}_{\mathrm{s}}$ & $\mathrm{mm}$ & 19 \\
Pre-forming Zone & $\mathrm{h}_{\mathrm{p}}$ & $\mathrm{mm}$ & 5 \\
Holding Zone & $\mathrm{d}_{\mathrm{h}}$ & $\mathrm{mm}$ & 13.5 \\
Pre-forming Angle & $\theta$ & $\mathrm{o}$ & 30 \\
\hline
\end{tabular}

Table 2.3 Aluminium Plate dimension

\begin{tabular}{lccc}
\hline \multicolumn{1}{c}{ Element } & Symbol & Unit & Dimension \\
\hline Plate thickness & $\mathrm{t}$ & $\mathrm{mm}$ & 1 \\
Plate width and length & $\mathrm{W} \times \mathrm{L}$ & $\mathrm{mm}$ & $70 \times 70$ \\
Diameter of pre-cut hole & $\mathrm{D}_{0}$ & $\mathrm{~mm}$ & 20 \\
Diameter of hole-flanging & $\mathrm{D}_{1}$ & $\mathrm{~mm}$ & 38 \\
Height of flanged collar & $\mathrm{h}$ & $\mathrm{mm}$ & $7-8$ \\
\hline
\end{tabular}

\subsection{Method and Process Strategy}

The parameters used to obtain the experimental data were divided by 2 and 3 levels. The experimental data were achieved by combining each level in every process parameter. Full factorial $2 \times 3 \times 3$ design were used to obtain the experimental data. The process parameters and its level were shown in table 2.4.

Table 2.4 Process parameters and levels

\begin{tabular}{cccc}
\hline $\begin{array}{c}\text { Process } \\
\text { Parameters }\end{array}$ & Level 1 & Level 2 & Level 3 \\
\hline$V_{\mathrm{f}}$ & $400 \mathrm{~mm} / \mathrm{min}$ & $700 \mathrm{~mm} / \mathrm{min}$ & - \\
$\Delta \mathrm{x} / \mathrm{y}$ & $1 \mathrm{~mm}$ & $1.25 \mathrm{~mm}$ & $2 \mathrm{~mm}$ \\
$\Delta \mathrm{x} / \mathrm{y}$ & $2 \mathrm{~mm}$ & $2.75 \mathrm{~mm}$ & $3.5 \mathrm{~mm}$ \\
\hline
\end{tabular}

Figure 2.4 illustrates the movement of the tool. Starting from the bottom plate which moves helically to the top of the plate. The feed speed $\left(v_{f}\right)$ is the speed of the tool moving helically from the bottom to the top of the helical path. The magnitude of the forming step toward the axial direction $(\Delta z)$ is the pitch of the movement of the conical forming tool to the $z$ axis. The magnitude of the forming step toward the radial direction $(\Delta x / y)$ is the distance between radial forming step. The radial forming step is the movement of the tool on the $x$-axis relative to the $y$-axis. The color difference in Figure 2.4 represents the forming stage occurred during each forming step. The number of forming stages during the process depends on the magnitude of the radial forming step size $(\Delta x / y) . D_{0}$, is the initial pre-cut hole diameter, $D_{1}$, is the final diameter of hole-flange, and $(h)$ is the height of the collar. 

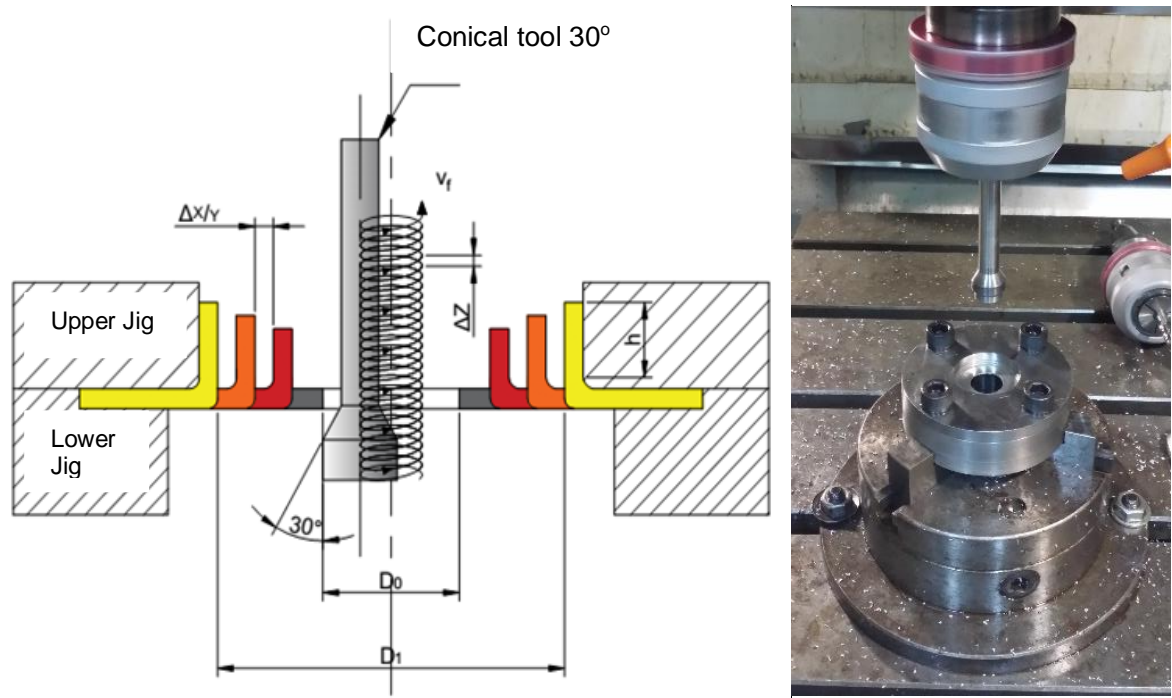

Figure 2.4 IIlustrate of IBHF process

Variance analysis was used to analyze the experimental data which consisting of two or more process parameters with two or more levels. The ANOVA table consists of the degrees of freedom $\left(d_{f}\right)$, sum of squares $(S S)$, the middle squares (mean of square, $M S)$ and $\mathrm{F}$ arithmetic $\left(F_{\mathrm{a}}\right)$. The parameter response in this research was collar height, $h$. Parameters set to constant were pre-cut diameter was set to $20 \mathrm{~mm}$ and produced by drilling using CNC milling machine, final hole-flange diameter was set to $38 \mathrm{~mm}$, and spindle speed was set as low as $50 \mathrm{rpm}$. The experiments were conducted by combining the process parameters contained in the CNC DAHLIH MCV 1020 BA milling machine, i.e. feed speed $\left(v_{f}\right)$, radial forming step size $(\Delta x / y)$, and axial forming steps size $(\Delta z)$.

The measurement of the observed height of the collar refers to Figure 2.5. The heights were measured on all four sides of the plate. The measurement results were averaged to produce more accurate data.
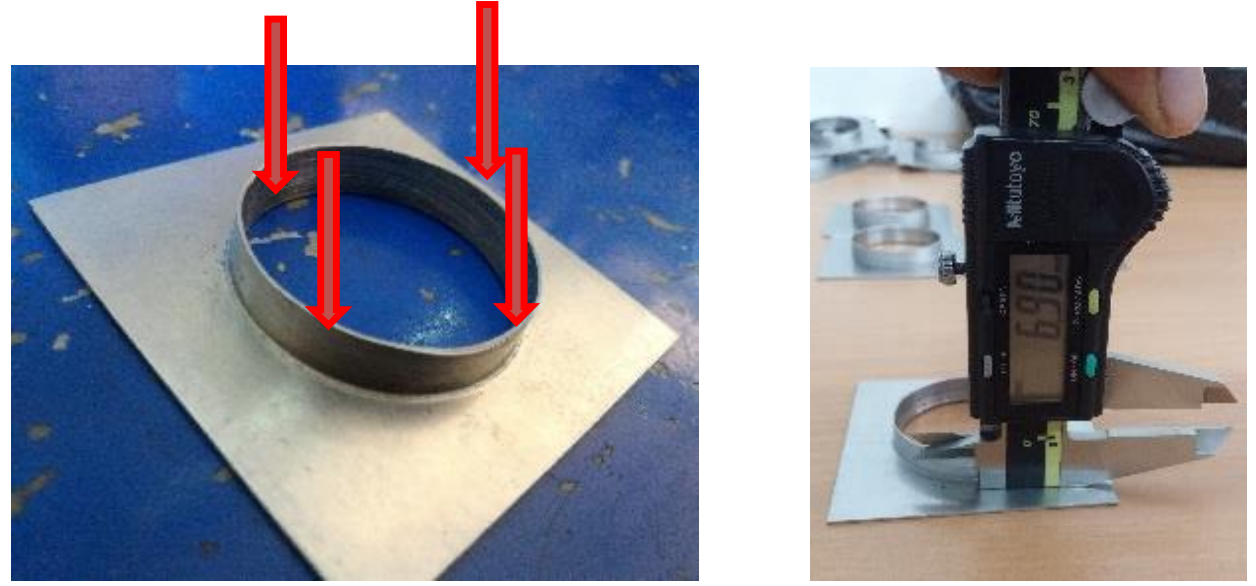

Figure 2.5 Measurement scheme.

\section{ResUlt AND Discussion}

The collar height data which produced using incremental backward hole flanging process can be seen in table 3.1. the $R 1$ and $R 2$ column represented two replications were used during experiment. The replication was the average of each measurement as shown in figure 2.5. Total 36 of specimens were measured during this research. 
Table 3.1 Experiment data result.

\begin{tabular}{cccccc}
\hline \multicolumn{2}{c}{ Process parameters } & \multicolumn{3}{c}{ Response parameter } \\
\hline $\begin{array}{c}\boldsymbol{V}_{\boldsymbol{f}} \\
(\mathbf{m m} / \mathbf{m i n})\end{array}$ & $\boldsymbol{\Delta}_{\mathbf{x} / \mathbf{y}}(\mathbf{m m})$ & $\boldsymbol{\Delta z}(\mathbf{m m})$ & \multicolumn{3}{c}{$\boldsymbol{h}(\mathbf{m m})$} \\
\cline { 4 - 6 } & & 2 & $\mathbf{R 1}$ & $\mathbf{R 2}$ & $\mathbf{A v g}$ \\
\hline 400 & 1 & 2.75 & 6.93 & 7.06 & 7.06 \\
& & 3.5 & 6.88 & 6.83 & 6.99 \\
& \multirow{2}{*}{1.25} & 2 & 7.19 & 7.19 & 7.19 \\
& & 2.75 & 7.02 & 6.99 & 7.00 \\
& & 3.5 & 6.98 & 6.94 & 6.96 \\
& 2 & 2 & 7.46 & 7.39 & 7.43 \\
& & 2.75 & 7.37 & 7.34 & 7.35 \\
& & 3.5 & 7.20 & 7.17 & 7.19 \\
& 1 & 2 & 7.03 & 7.11 & 7.07 \\
& & 2.75 & 7.03 & 6.99 & 7.01 \\
& & 3.5 & 6.90 & 6.90 & 6.90 \\
& \multirow{2}{*}{1.25} & 2 & 7.19 & 7.13 & 7.16 \\
& & 2.75 & 7.04 & 6.99 & 7.01 \\
& & 3.5 & 6.94 & 6.95 & 6.95 \\
& 2 & 2 & 7.41 & 7.42 & 7.42 \\
& & 2.75 & 7.37 & 7.21 & 7.29 \\
& & 3.5 & 7.27 & 7.11 & 7.19 \\
\hline
\end{tabular}

The data from the experimental results were tested statistically to find out which process parameters significantly influence toward the response parameter. Analysis of variance (ANOVA) was used to determine whether the feed speed, radial forming step size, and axial forming step size had a significant influence on the height of the collar. The variance analysis table (ANOVA) process parameters to the collar height calculations are shown in table 3.2 below.

Table 3.2 ANOVA result.

\begin{tabular}{cccccc}
\hline Source & df & SS & MS & F $_{\text {test }}$ & P-value \\
\hline $\mathrm{V}_{\mathrm{f}}$ & 1 & 0.000042 & 0.000042 & 0.05 & 0.828 \\
$\Delta^{\times} / \mathrm{y}$ & 2 & 0.368189 & 0.184095 & 217.19 & 0.000 \\
$\Delta \mathrm{z}$ & 2 & 0.138194 & 0.069097 & 81.52 & 0.000 \\
Error & 12 & 0.010172 & 0.000848 & & \\
Total & 17 & 0.516597 & & & \\
\hline
\end{tabular}

$P$-value indicates which process parameters have significant influence toward collar height produced by IBHF process. P-value smaller than level of significant $(\alpha)$ indicates that the process parameter has a significant effect toward response parameter. In this study, $\alpha=5 \%$ was used. The statically interpretations using P-value for the process parameters influence were shown in Table 3.2. Process parameter feed speed $\left(v_{f}\right)$, Pvalue $=0.828>\alpha=0.05$, statistically $\left(v_{f}\right)$ has no significant effect toward height of the collar. Process parameter radial forming step size $(\Delta x / y)$, P-value $=0.000<\alpha=0.05$, statistically parameter $(\Delta x / y)$ has significant influence. Process parameter radial forming step size $(\Delta z)$ P-value $=0.000<\alpha=0.05$, statistically parameter $(\Delta z)$ has significant influence toward collar height. 
Graphically, the relationship between the feed speed parameter $\left(v_{f}\right)$, the radial forming step size $(\Delta x / y)$, and the axial forming step size $(\Delta z)$ towards collar height were shown in Graphic 3.1 below.

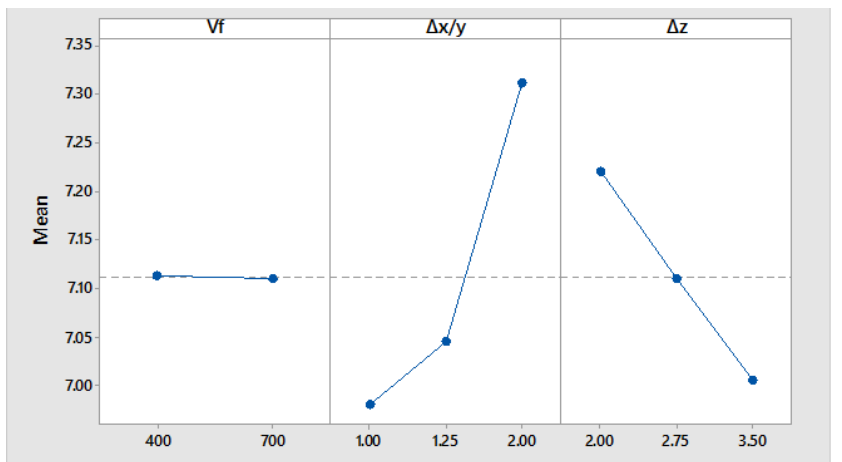

Graphic 3.1 Main effect plot, process parameters toward collar height.

Graphic 3.1 main effect plot, shows that the feed speed $\left(v_{t}\right)$ unaffecting the height of the collar. However, a large increase in the radial forming step size $(\Delta x / y)$ will increase the value of the collar height. The greater the forming step in the axial direction $(\Delta z)$, decrease the value of the collar height in the incremental backward hole-flanging process. The axial forming step size setting which value equal to $2 \mathrm{~mm}$ or less, can produce maximum collar height. Because the strain rate that occurred is low, then the increase in material stress will be low as well. Due to the low material stress, strain can be achieved as much as possible [5]. This low strain rate can be indicated from the smaller step size that forming toward axial direction. In the radial forming direction, setting of the parameter which value $2 \mathrm{~mm}$ or more can produce maximum collar height. This relates to the forming mechanism, whereby maximum strain can be achieved when forming area is larger [1] [5]. The larger forming area can be indicated from large forming step toward radial direction then number of steps to produce hole-flange was less.

\section{Conclusions}

Based on experimental results and analysis that have been done in this research, it can be concluded as follows:

1. The value of the feed speed ( $\underline{v}$ ) has no significant effect on the collar height of the IBHF process.

2. The larger value of the radial forming step $(\Delta x / y)$ increases the value of the collar height of the IBHF process.

3. The larger value of axial forming step $(\Delta z)$ will decrease the value of the collar height in the IBHF process.

\section{REFERENCES:}

[1] A. Petek and K. Kuzman, "Backward Hole-Flanging Technology Using an Incremental Approach," Strojniški Vestn. - J. Mech. Eng., vol. 58, no. 2, pp. 7380, 2012.

[2] Z. Cui and L. Gao, "Studies on hole-flanging process using multistage incremental forming," CIRP J. Manuf. Sci. Technol., vol. 2, no. 2, pp. 124-128, 2010.

[3] G. Centeno, M. B. Silva, V. A. M. Cristino, C. Vallellano, and P. A. F. Martins, "Hole-flanging by incremental sheet forming," Int. J. Mach. Tools Manuf., vol. 59, pp. 46-54, 2012.

[4] G. Hirt, J. Ames, M. Bambach, R. Kopp, and R. Kopp, "Forming strategies and 
Process Modelling for CNC Incremental Sheet Forming," CIRP Ann. - Manuf. Technol., vol. 53, no. 1, pp. 203-206, 2004.

[5] M. Bambach, H. Voswinckel, and G. Hirt, "A new process design for performing hole-flanging operations by incremental sheet forming," Procedia Eng., vol. 81, no. October, pp. 2305-2310, 2014.

[6] T. Cao, B. Lu, H. Ou, H. Long, and J. Chen, "Investigation on a new hole-flanging approach by incremental sheet forming through a featured tool," Int. J. Mach. Tools Manuf., vol. 110, pp. 1-17, 2016.

[7] M. Borrego, D. Morales-Palma, A. J. Mart??nez-Donaire, G. Centeno, and C. Vallellano, "On the Study of the Single-stage Hole-flanging Process by SPIF," Procedia Eng., vol. 132, pp. 290-297, 2015.

[8] M. Borrego, D. Morales-Palma, A. J. Martínez-Donaire, G. Centeno, and C. Vallellano, "Experimental study of hole-flanging by single-stage incremental sheet forming," J. Mater. Process. Technol., vol. 237, pp. 320-330, 2016.

[9] T. Wen, S. Zhang, J. Zheng, Q. Huang, and Q. Liu, "Bi-directional dieless incremental flanging of sheet metals using a bar tool with tapered shoulders," J. Mater. Process. Technol., vol. 229, pp. 795-803, 2016. 